\title{
The narial morphology of Metarhinus and Sphenocoelus (Mammalia, Perissodactyla, Brontotheriidae)
}

\author{
Bryn J. Mader
}

\begin{abstract}
The brontothere genera Metarhinus and Sphenocoelus (= Dolichorhinus) are both characterized by an unusual redirection of the air passageway in which the internal nares are effectively closed off and new openings that serve as the functional internal nares have appeared posteriorly. Rather than passing lateral to the vomer, the airstream appears to pass over or through the bone (thus bypassing the anatomical internal nares) and exits through an enlarged vomerine notch. If correctly interpreted, this morphology is unique among mammals. In the past it has been suggested that the posterior displacement of the internal nares is either an amphibious adaptation or an adaptation to enhance olfaction. The current paper favors the latter interpretation. Among other reasons is that the change in morphology channels the airstream directly toward the olfactory epithelium in the area of the ethmoid. In order for the vomer to channel air, the septal cartilage would require significant modification. It is speculated here that the respiratory septum (vomer, crest of the maxilla, and crest of the palatine) might have been wholly or partially isolated from the olfactory septum (perpendicular plate of the ethmoid and septal cartilage), allowing air to be channeled through (or over) the vomer.
\end{abstract}

Bryn J. Mader. Department of Biological Sciences and Geology, Queensborough Community College, 22205 56th Avenue, Bayside, NY, 11364-1497, USA. bmader@qcc.cuny.edu

Keywords: titanothere; Dolichorhinus, vomer; nasal breather; nasal cycle; evo-devo

Submission: 26 August 2018 Acceptance: 18 January 2019

\section{INTRODUCTION}

The brontothere genera Metarhinus and Sphenocoelus are both characterized by an unusual redirection of the air passageway in which the internal nares are effectively closed off and new openings that serve as the functional internal nares have appeared posteriorly. Riggs (1912) was the first to recognize this in Sphenocoelus (= Dolichorhinus), although he assigned the attribute to a single species only. Peterson (1924, p. 442-443) recognized the broader distribution of the trait, regarding it as a generic rather than a specific

Mader, Bryn J. 2019. The narial morphology of Metarhinus and Sphenocoelus (Mammalia, Perissodactyla, Brontotheriidae).

Palaeontologia Electronica 22.1.8A 1-15. https://doi.org/10.26879/919

palaeo-electronica.org/content/2019/2417-narial-morphology 
character. Peterson also more fully described the anatomy (p. 409) noting peculiar pouch-like structures (choanal pouches of Mader, 2008, and Mihlbachler, 2008) that close off the internal nares and re-direct the air stream posteriorly to exit at a new opening between the pterygoid processes. Osborn (1929) identified the choanal pouches of Sphenocoelus as maxilloturbinates, as did Mihlbachler (2008).

In 1981, an extremely well-preserved Metarhinus skull was collected by L. Shields of the University of Colorado. The skull was preserved in an exceptionally soft matrix, which made it possible to prepare out structures that, otherwise, could not have been examined. This included structures in the internal nares similar to those of Sphenocoelus. A bony structure projecting from the internal nares between the pterygoids in the same general location as the choanal pouches of Sphenocoelus was interpreted by Mihlbachler (2008) as posteriorly displaced turbinates. However, Mader (2009) identified this same structure as a greatly enlarged vomer. Mader noted that the internal nares were essentially closed off and that an opening posterior to the enlarged vomer was the functional exit for the airstream. Mader identified that opening as a highly modified vomerine notch. The purpose of the present paper is to review and expand upon the interpretations of these structures given by Mader $(2008,2009)$ and to further explore their possible functional significance.

\section{METHODS}

The taxonomy employed in the present paper follows that of Mader $(1998,2008)$, which differs somewhat from that of Mihlbachler (2008), the other major recent reviser of North American brontotheres.

Institutional abbreviations. AMNH, American Museum of Natural History, New York, New York, USA; FMNH PM, Field Museum of Natural History, Chicago, Illinois, USA; UCM, University of Colorado Museum, Boulder, Colorado, USA.

\section{Narial Morphology of Typical Mammals}

The following description of the narial morphology in typical mammals is an expansion of the description given by Mader (2009). In most mammals the vomer forms a thin, vertical plate that is part of the nasal septum and helps divide the posterior nasal cavity into right and left sides. The nasal septum is also composed of the perpendicular plate of the ethmoid, the septal cartilage, the crest of the maxilla, and the crest of the palatine. In many mammals (e.g., Equus, Camelus, Panthera) there is a prominent anterior-posterior channel that runs down the length of the vomer medially. The dorsal part of this channel is open anteriorly where the bone articulates with the premaxilla (thus presenting a u-shaped cross section), but may be closed posteriorly, thus forming a hollow tube. The septal cartilage fits into this u-shaped channel (= septal groove) and extends up to the dorsal roof of the nasal cavity as a continuous sheet.

Normally the air stream passes laterally on each side of the vomer before exiting the nasal cavity through the internal nares (= choanae). In many mammals the vomer forks posteriorly where it joins the presphenoid (vomerine wings or alae) leaving a small, roughly triangular space between the two bones known as the vomerine notch (see Eisenmann et al., 1988, figure 1). The vomerine notch is also known by the Latin name, incisura vomeris (Sisson, 1910).

This vomerine notch is found in equids (e.g., Equus caballus), thus indicating its presence among Perissodactyla, but is also found in felids (e.g., Panthera leo, Felis concolor, Felis sylvestris), and canids (e.g., Canis lupus). The vomerine notch in horses is rather small, but its morphology in cats and dogs may help to explain how the condition in dolichorhinine brontotheres (sensu Mader, 1989, 1998, and 2008) could have evolved. It will be noted from the lion skull pictured in Figure 1, that there is a distinct gap between the presphenoid and vomer, and it is only the alae of the vomer that approach the anterior edge of the presphenoid. This large opening marks the exit of the anteriorposterior channel of the vomer noted above. Hence, in osteological preparations (where the septal cartilage is not preserved) there is a continuous open passageway running through the interior of the vomer from the nasal cavity to the vomerine notch. It is speculated here that this passage through the vomer became the functional air passageway in certain members of the Dolichorhininae.

Dissection of the domestic cat (Felis catus) performed for this study indicates that, in the living animal, the area of the vomerine notch lies within the nasopharynx, dorsal to the soft palate (the soft palate must be removed in order to inspect the area). The epithelial tissue covering the presphenoid/vomer area is thin and appears to be continuous and uninterrupted. There is no perforation through the soft tissue allowing the vomerine notch to communicate directly with the nasopharynx. Therefore, if this became the air passageway in 


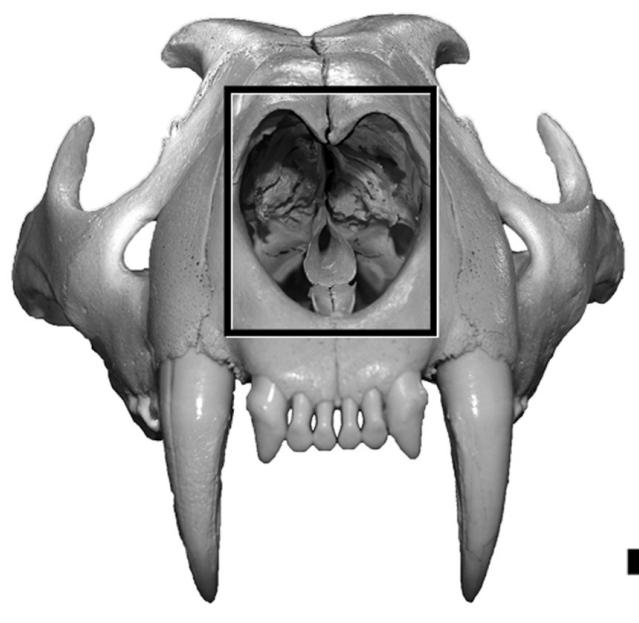

1
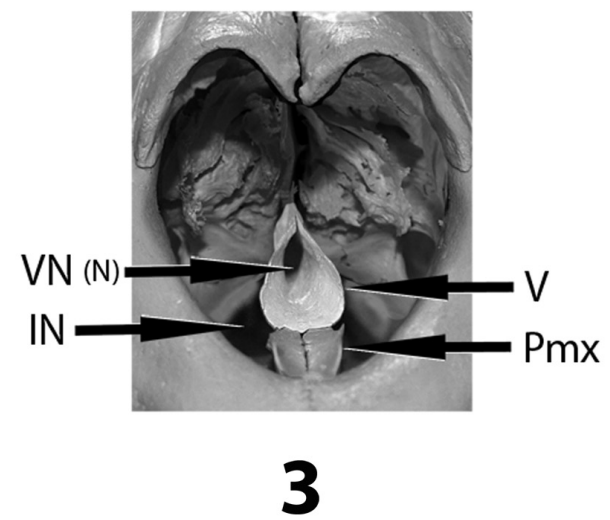
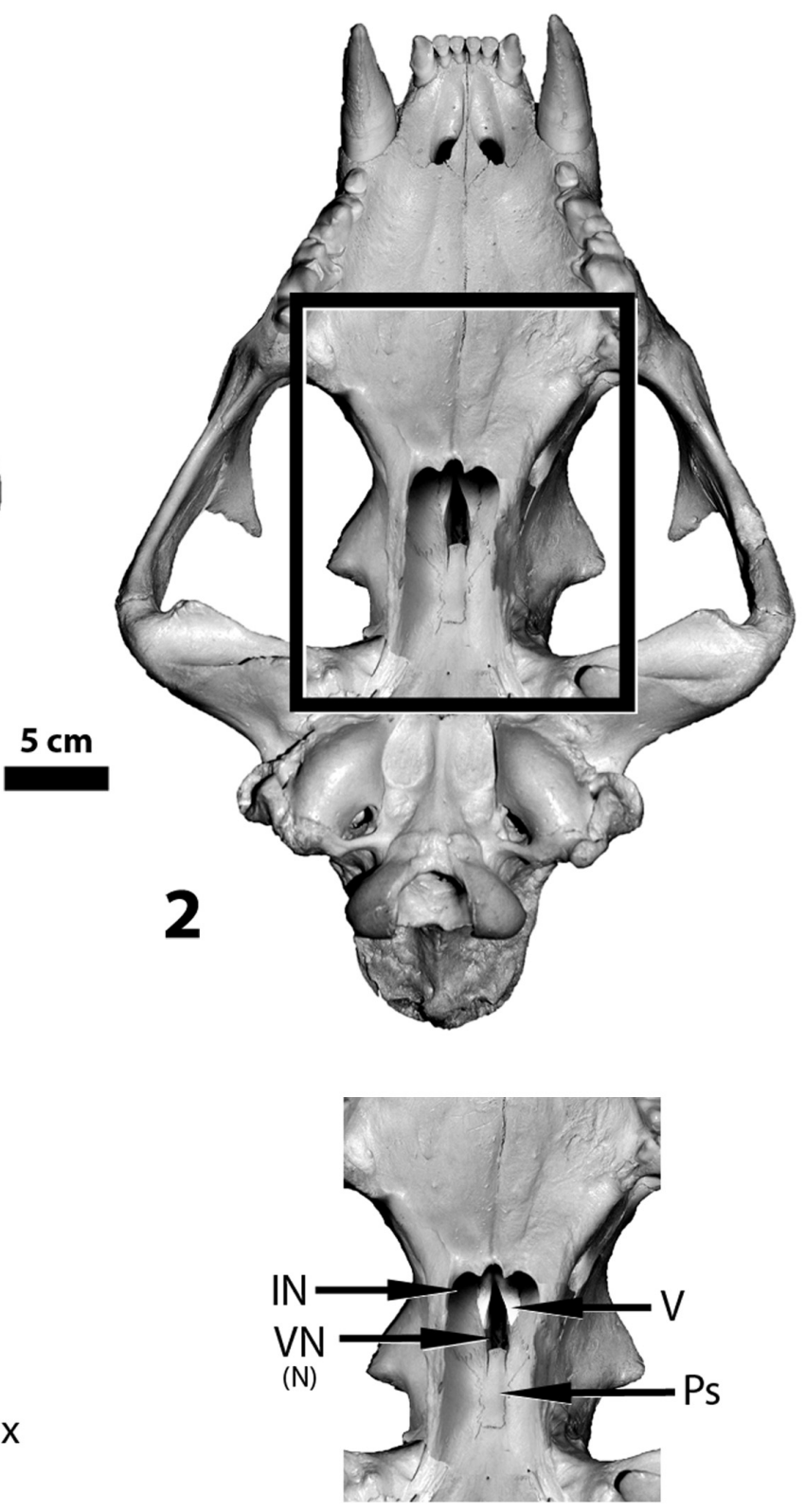

4

FIGURE 1. Skull of African Lion (Panthera leo, author's private collection) showing anatomy of vomer and vomerine notch. Turbinates in this specimen are largely missing. 1, anterior view; 2, ventral view; 3, detail of anterior nasal cavity; 4, detail of internal narial region. Abbreviations: IN, internal nares; Ps, presphenoid; V, vomer; VN, vomerine notch, the presumed functional internal nares $(\mathrm{N})$ in all other figures. Rectangles superimposed on upper photographs show areas of detail below. In $\mathbf{3}$ and $\mathbf{4}$ the vomer has been lightened for better clarity.

certain dolichorhinine brontotheres, a perforation in the soft tissue would have had to evolve.

The turbinates (or conchae) are usually elaborate scrolls of very thin bone that fill most of the interior of the nasal cavity on either side of the nasal septum. There are three pairs of turbinates altogether: a dorsal pair, a middle pair, and a ven- tral pair. The ventral pair project from the lateral walls of the nasal cavity from the maxillae and are known as maxilloturbinates. The two pairs located above this (i.e., the middle pair and dorsal pair) project from the ethmoid bone and are, thus, ethmoturbinates. 


\section{SYSTEMATIC PALEONTOLOGY}

Order PERISSODACTYLA Owen, 1848

Family BRONTOTHERIIDAE Marsh, 1873

Subfamily DOLICHORHININAE Riggs, 1912

Genus METARHINUS Osborn, 1908

v. 1912 Rhadinorhinus Riggs, p. 36-37, pl. 11 (figs. 2-3) (original description).

v. 1914 Heterotitanops Peterson, p. 53-57, figs. 1-2, pl. 11 (original description).

v. 2008 Fossendorhinus Mihlbachler, p. 63-69, figs. 24-26 (new generic name).

\section{Narial Morphology in Metarhinus}

Mader (2008) recognized two species of Metarhinus as valid: $M$. fluviatilis and $M$. diploconus (=M. abbotti). A third species of Metarhinus, $M$. pater, may also be valid (see Discussion, below). The following description of the narial morphology of Metarhinus is based on a single remarkably preserved skull (UCM 44939) referable to $M$. fluviatilis.

The description of UCM 44939 presented here reviews and expands upon the description given by Mader (2009). In this specimen, the internal nares are virtually blocked off from the nasal cavity with only two tiny openings lateral to the vomer (presumably on each side of it) allowing for the possible passage of air (see Mader, 2009, figure 4). Hence, the floor of the nasal cavity forms an almost uninterrupted sheet of thin bone as it extends posteriorly from the external nares. The internal nares, therefore, appear to be functionally useless and the air passageway redirected over them.

The internal nares are located medial to the anterior part of M3 (Figure 2). At the anterior margin of the internal nares, there is a distinct depression in the palate. As observed by Osborn (1929), in describing Sphenocoelus (= Dolichorhinus), this structure is formed by a slight backward and upward extension of the dorsal surface of the palatine. Osborn referred to this structure as a "secondary palatal plate," while figures in Mader (2009 and the present paper) label the structure as the "palatal depression."

Posterior to the location of the internal nares is the main body of the vomer, which is a complex, v-shaped structure over which the functional airway seems to pass. Hence, it appears that the airway no longer passes lateral to the vomer (as it does in most mammals), but rather through its center. The presumed air passageway then exits through an enlarged opening posterior to the main body of the vomer and anterior to the presphenoid (labelled "N" in Figure 2). This opening is in the exact location of the vomerine notch found in horses and some other mammals and is identified by Mader (2009 and the present paper) as such.

Regarding the vomer, the identity of this bone was most evident when the skull was apart (prior to restoration), and it could be readily viewed from multiple angles. However, this same bone was identified as posteriorly shifted turbinates by Mihlbachler (2008). That this bone does not represent the turbinates (although that is a worthy idea) is suggested by the fact that it appears to be a single, un-paired structure (Mader, 2009) and is joined from below by a vertical extension of the palatine. Furthermore, even though all of the matrix was removed from the nasal cavity, no turbinates were discovered therein. Thus, it would seem unlikely to find the delicate turbinates preserved in the relatively exposed pterygoid region, but not in the more sheltered confines of the nasal cavity itself.

In UCM 44939, as in most brontotheres, there is evidence of a stiff flange of bone that protrudes ventrally between the pterygoids. Although this structure has been named the "vomerine" plate (Peterson, 1924), it appears to incorporate the basisphenoid, presphenoid, as well as the vomer itself (Mader, 1998). Normally, the "vomerine" plate extends from the internal nares to the anterior edge of the basicranium, but, because of breakage, it is only well-preserved on the basisphenoid of UCM 44939. Based on the morphology of Sphenocoelus, however (see below), the plate probably extended through the area of the vomerine notch, bisecting it prior to contacting the vomer.

Figure 3 presents a semi-diagrammatic interpretation of the skull of Metarhinus, as it may have appeared in sagittal section. This reconstruction is based primarily on UCM 44939, but also reflects information obtained from FMNH PM 1732, a partial skull (described and figured by Mader, 2009). The diagram does not show the septal cartilage or turbinates, which are not preserved in the specimen.

As the air stream passes posteriorly from the external nares it is directed over (or, perhaps, through) the vomer toward the rear of the nasal cavity. It will be noted from the diagram that the functional air passageway $(\mathrm{N})$ emerges well posterior to the anatomical internal nares (IN). Prior to exiting, the airstream would be pointed directly toward the ethmoid, the location of the olfactory epithelium. 

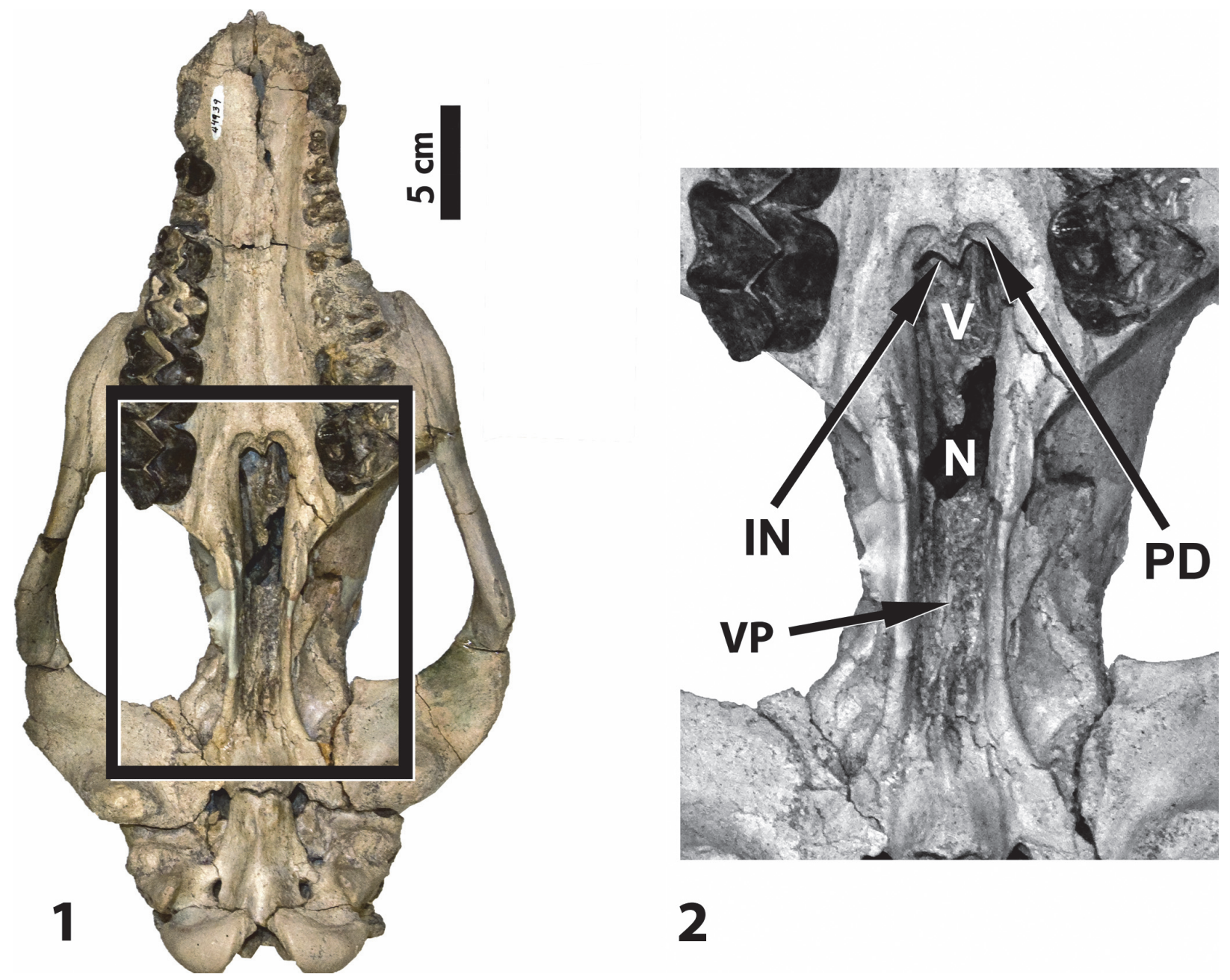

FIGURE 2. Skull of Metarhinus (UCM 44939). 1, entire skull in ventral view; 2, enlargement of the nasopharyngeal region. Rectangle superimposed on left photograph shows area of detail. Abbreviations: IN, internal nares (non-functional); N, functional internal nares (presumably the vomerine notch); PD, palatal depression (secondary palatal plate); V, vomer; VP, vomerine plate.

\section{Genus SPHENOCOELUS Osborn, 1895}

\section{v. 1895 Dolichorhinus Hatcher, p. 1090 (new generic} name).

v. 1926 Tanyorhinus Cook, p. 13-16, pl. 1-6, 10 (original description).

\section{Narial Morphology in Sphenocoelus}

Mader (2008) recognized three species of Sphenocoelus as valid: S. uintensis, S. intermedius, and $S$. hyognathus. This description is based on three specimens (AMNH 13164, AMNH 1851, and AMNH 1852) referred to $S$. hyogathus. Sphenocoelus intermedius is very similar to $S$. hyognathus, although smaller in size, and, owing to their morphological similarity, it is likely that the characteristics described herein would apply to that species as well. Sphenocoelus uintensis, however, is more primitive, and it is unclear as to what extent these characters would apply to that taxon.

AMNH 13164 (Figure 4) is a skull in which the internal nares are particularly well preserved. To facilitate a description of the morphology, a photographic reconstruction of the ventral portion of the skull was produced using Photoshop (CS3 extended version). Figure 4.1 shows the specimen the way it actually appears, and Figure 4.2-4.3 show the reconstruction.

To produce this reconstruction, the original photographic image was skewed to correct for taphonomic deformation. Then, the more complete right side of the specimen was copied and reversed to create a mirror image. The images were spliced together, and the resulting picture was then compressed laterally to adjust the skull 


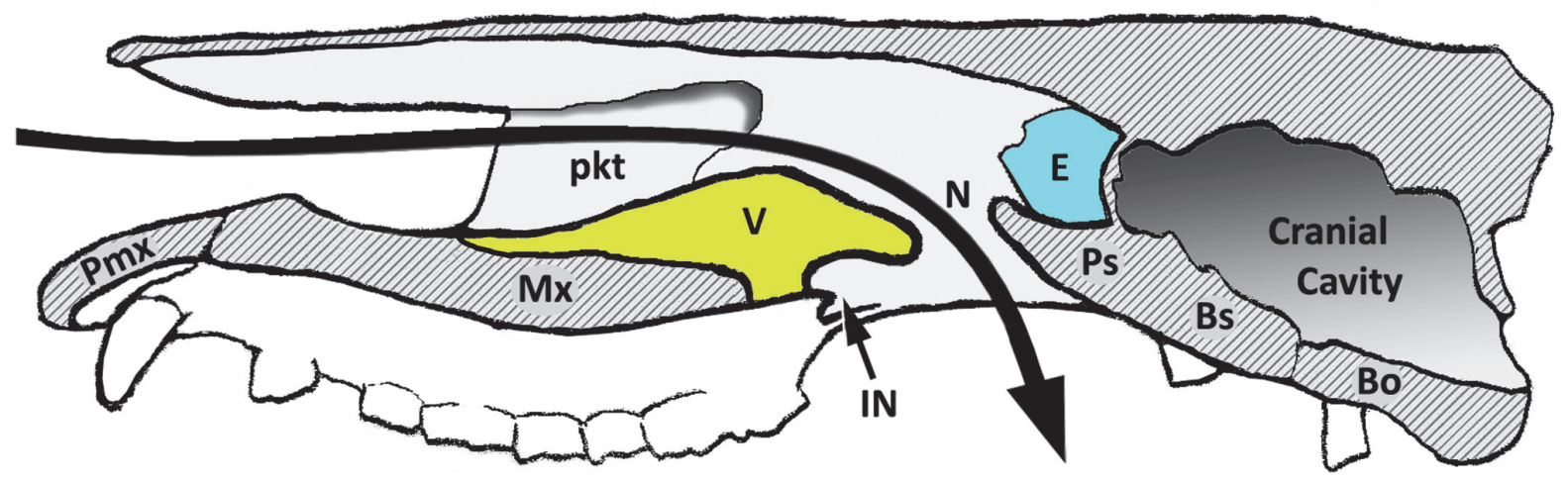

$10 \mathrm{~cm}$

FIGURE 3. Semi-diagrammatic reconstruction of the skull of Metarhinus seen in sagittal section (based on UCM 44939 and FMNH PM 1732). Abbreviations: Bo, basioccipital; Bs, basisphenoid; E, ethmoid; IN, anatomical internal nares (non-functional); $\mathrm{Mx}$, maxilla; $\mathrm{N}$, functional internal nares (vomerine notch); pkt, blind pocket in lateral wall of nasal cavity; Pmx, premaxilla; Ps, presphenoid; V, vomer. Large arrow shows air pathway through the nasal cavity. Dark gray areas with hatch marks indicate cut surfaces.

width. Finally, the occipital region was warped to narrow it further. The resulting image is a reasonable reconstruction of what the original skull may have appeared like when fully intact and prior to any post-mortem distortion.

As will be noticed from Figure 4 (both the specimen as it actually appears and in the reconstruction) the narial structures of Sphenocoelus are essentially the same as those of Metarhinus, but are far more exaggerated. Hence the palatal depression is much larger and sweeps further backward, approaching the posterior part of M3. As a result, the anatomical internal nares are posteriorly displaced.

Passing posteriorly from the anatomical internal nares is the so-called "vomerine" plate, surrounded on both sides by bony pouches (choanal pouches of Mader, 2008, and Mihlbachler, 2008). Mihlbachler suggested that these pouches are the maxilloturbinates (apparently following Osborn, 1929), but they are here interpreted as part of a greatly expanded and complex vomer (as in Metarhinus). Thus, the vomer not only includes the raised keel-like structure running between the pterygoids medially ("vomerine" plate), but also the choanal pouches lateral to that keel.

The "vomerine" plate extends beyond the vomer, bisecting the opening posterior to it, which is the presumed functional air passageway (as noted by Peterson, 1924), and is here interpreted as the vomerine notch. The "vomerine" plate terminates at the basicranium as in other brontotheres.
The part of the "vomerine" plate that bisects the vomerine notch is probably composed of the presphenoid.

Figure 5 shows AMNH 1851, a skull of Sphenocoelus that has been sagittally sectioned. The section drifts from left to right: beginning slightly to the left of center in the occipital region and passing slightly to the right of center in the orbital and palatal regions (this is most evident in dorsal view). Thus, the section is mid-sagittal near to the bases of the zygomatic arches, but slightly parasagittal elsewhere. Viewed dorsally, the angle of the section changes at the base of the nasals by about 5 degrees so that the right and left nasals are separated from each other without either being damaged. Most of the rostrum below the nasals is parasagittally sectioned (slightly to the right of center), but as the incisive border is approached, the section again becomes midsagittal so that the space between the first incisors is precisely bisected. At most locations the parasagittal section appears to be no more than 3-4 $\mathrm{mm}$ off of the medial plane. The maximal deviation from the medial plane occurs on the dorsal surface between the orbits at the base of the nasals where the plane of section passes about $6.0-6.5 \mathrm{~mm}$ from the midline. This maximal deviation occurs on the dorsal surface only; on the ventral surface the deviation in the same area is only about $3-4 \mathrm{~mm}$. The difference between dorsal and ventral measurements is probably due to taphonomic deformation rendering the skull less than perfectly symmetrical. 

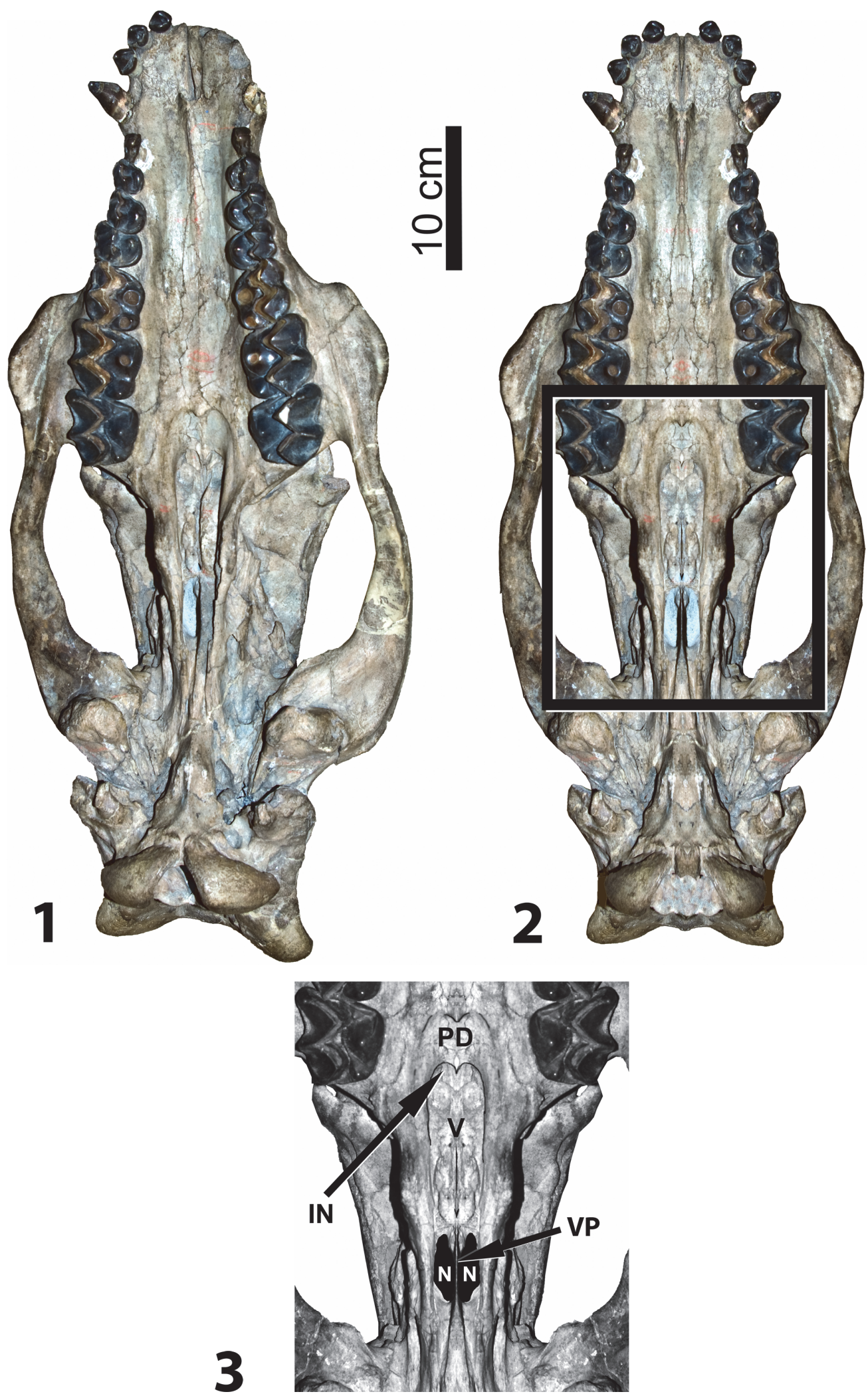

FIGURE 4. AMNH 13164, skull of Sphenocoelus (= Dolichorhinus) in ventral view. 1, Skull as it actually appears; 2 , reconstruction of skull showing how it might have appeared when fully intact and prior to taphonomic distortion; $\mathbf{3}$, detail of reconstructed internal narial region (functional internal nares darkened). Rectangle superimposed on right photograph shows area of detail. Abbreviations: IN, anatomical internal nares (non-functional); N, functional internal nares (vomerine notch); PD, palatal depression (secondary palatal plate); V, vomer; VP, vomerine plate. 

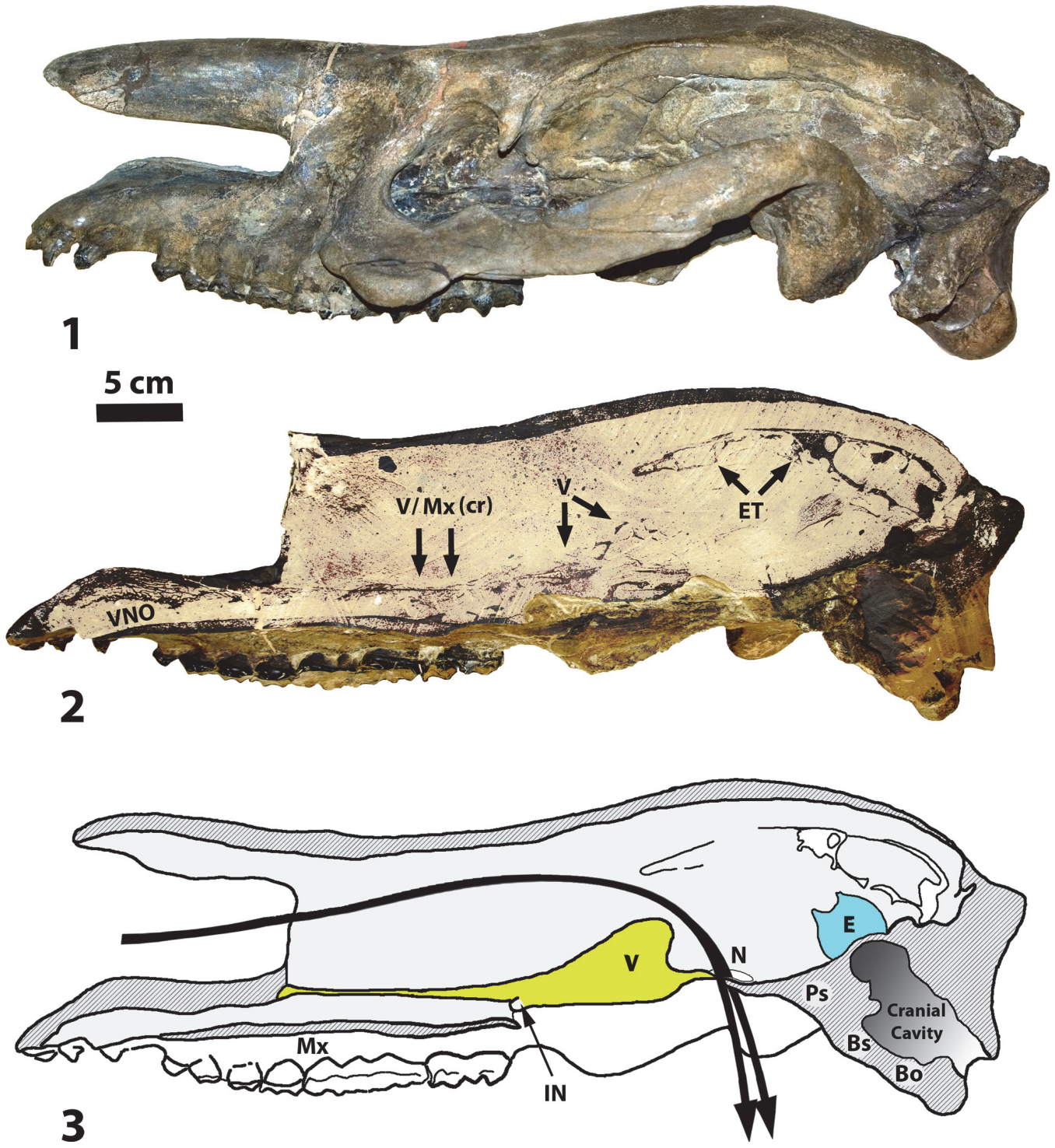

FIGURE 5. AMNH 1851, skull of Sphenocoelus (= Dolichorhinus). 1, left side of skull showing external morphology; 2 , right side of skull showing sagittal section (nasal is removed and matrix artificially lightened for better contrast); $\mathbf{3}$, semi-diagrammatic reconstruction of sagittal section showing presumed air stream. Abbreviations: Bo, basioccipital; Bs, basisphenoid; E, ethmoid; ET, ethmoturbinate; IN, anatomical internal nares (non-functional); Mx, maxilla; Mx (cr), crest of maxilla; N, functional internal nares (vomerine notch); Ps, presphenoid; V, vomer; VNO, area of vomeronasal organ.

As shown in Figure 5, the nasal cavity is large and fills most of the interior volume of the skull. There are small chips of bone throughout this chamber that would have come from a variety of delicate nasal structures damaged post mortem and mixed with the matrix-forming sediment.

In the ventral part of the cavity are remnants of the nasal septum. Anteriorly, over the molar series, and elevated over the floor of the nasal cavity, is the vomer. At this location the section is only about $3-5 \mathrm{~mm}$ to the right of the midline, so the section may also have captured the crest of the maxilla. Posterior to this, the section draws closer to the midline as the vomer elevates. If all the bone fragments in this part of the nasal cavity (overlying the pterygoids) represent the same bone, the vomer was evidently large and complex. Osborn (1929, figure 254 C) identified these same fragments as representing the maxilloturbinates, which seems unlikely given the more lateral location of those structures in mammals such as the horse and the doubtfulness of them being well-repre- 
sented in a mid-sagittal (or near mid-sagittal) section. Furthermore, the fragments appear to continue the sloping contour of the nasal septum, and I believe they are part of that structure.

The internal nares are not particularly evident in the photograph of AMNH 1851 (Figure 5.2), but their position is indicated on the semi-diagrammatic reconstruction appearing in Figure 5.3 (based on both AMNH 1851 and AMNH 13164). This reconstruction shows the air stream bypassing the internal nares (IN) as it passes over (or through) the vomer to exit at the vomerine notch (N). The diagram shows the air stream splitting as it passes through the notch since the vomerine plate bisects that opening. Just prior to exiting into the nasopharynx, the airstream would be moving in the general direction of the ethmoid.

Toward the roof of the posterior part of the nasal cavity is a structure that I believe to be an ethmoturbinate $(E T)$, presumably the dorsal concha. The sagittal section in this region runs from midsagittal to parasagittal, with the parasagittal section deviating 3-4 $\mathrm{mm}$ to the left of the midline. In the horse, the dorsal conchae lie closer to the midline than do the ventral conchae (maxilloturbinates). If the anatomy of Sphenocoelus was similar, it might explain how the ethmoturbinates could be represented in a nearly midsagittal section. That this structure represents an ethmoturbinate is also suggested by a second specimen of Sphenocoelus, AMNH 1852 (see below).

In AMNH 1852 (Figure 6.1-2) the skull has been transversely sectioned through the anteriormost part of the braincase in the region of the olfactory bulbs. Matrix covering the cribriform plate has been removed, but the remainder of the section is flat and polished. Extending dorsally from the cleft between the cribriform plates and following the medial plane is a thin partition of bone, the perpendicular plate of the ethmoid $(E)$. The perpendicular plate extends upward, approximately $3.5 \mathrm{~cm}$. Bits of bone on either side of it appear to be remnants of the ethmoidal labyrinth (= lateral masses). Dorsal to the perpendicular plate, the nasal cavity extends another $2.5 \mathrm{~cm}$ to the dorsal roof of the skull where the nasal cavity forks to form a broad Y-shape. The skull roof is remarkably thin in this area, especially at the terminus of each fork, where the bone is no more than $1 \mathrm{~mm}$ thick.

Dorsal to the cribriform plates at a level approximately parallel to the top of the perpendicular plate of the ethmoid (E), are two hollow structures that are very thin-walled laterally and ventrally, but are bound dorsally by the thick bone that forms the lateral skull roof. They appear to represent the ethmoturbinates (ET), which were also noted in the sagittal section, discussed above. Thus, the space contained within each is the dorsal conchal bulla (DCB) and the forked part of the nasal cavity located dorsomedially is the dorsal nasal meatus (DNM). These structures may also be identified in the sagittal section shown in Figure 6.3 (representing AMNH 1851). The thin, vertical, and slightly slanted line in Figure 6.2 roughly approximates the plane of the sagittal section shown in Figure 5.2, although it is slightly further from the midline (about $9 \mathrm{~mm}$ as opposed to 3-4 $\mathrm{mm}$ ). It should be noted that Figure 6.3 shows structures that would not be visible in that sagittal section.

\section{DISCUSSION}

If correctly interpreted, the narial morphology in Metarhinus and Sphenocoelus is unique among mammals. Extensive modifications reroute the air passageway in these forms and push the functional internal nares far posteriorly. In essence, the original internal nares are closed off and a new set has evolved. Mihlbachler (2008) has demonstrated a similar morphology in Telmatherium and, in my opinion, this suggests that Metarhinus, Sphenocoelus, and Telmatherium might all be included in a single monophyletic clade. Additional cladistic analysis would be necessary to properly evaluate this possibility.

In both Metarhinus and Sphenocoelus, the original margin of the internal nares appears to have been parallel to the anterior edge of $\mathrm{M} 3$ as it is in most brontotheres. However, in both genera there is also a posterior extension of the palatine (the secondary palatal plate or palatal depression) that pushes the internal nares further posteriorly. In Metarhinus this is very slight, but in Sphenocoelus it is quite pronounced so that the margin of the internal nares is now parallel to the back of $M 3$ in AMNH 13164. Mihlbachler (2008) noted that there are specimens of Sphenocoelus in which the margin of the internal nares is well behind M3.

In both Metarhinus and Sphenocoelus the internal nares appear to be virtually closed off. In describing Metarhinus, Mader (2009) identified two tiny apertures that directly connect the nasal cavity to the internal nares, and it is hard to believe that a significant amount of air could pass through these openings. No specimen of Sphenocoelus described so far has allowed for a detailed examination of the interior of the internal nares, but the greatly expanded vomer appears to fill almost the 


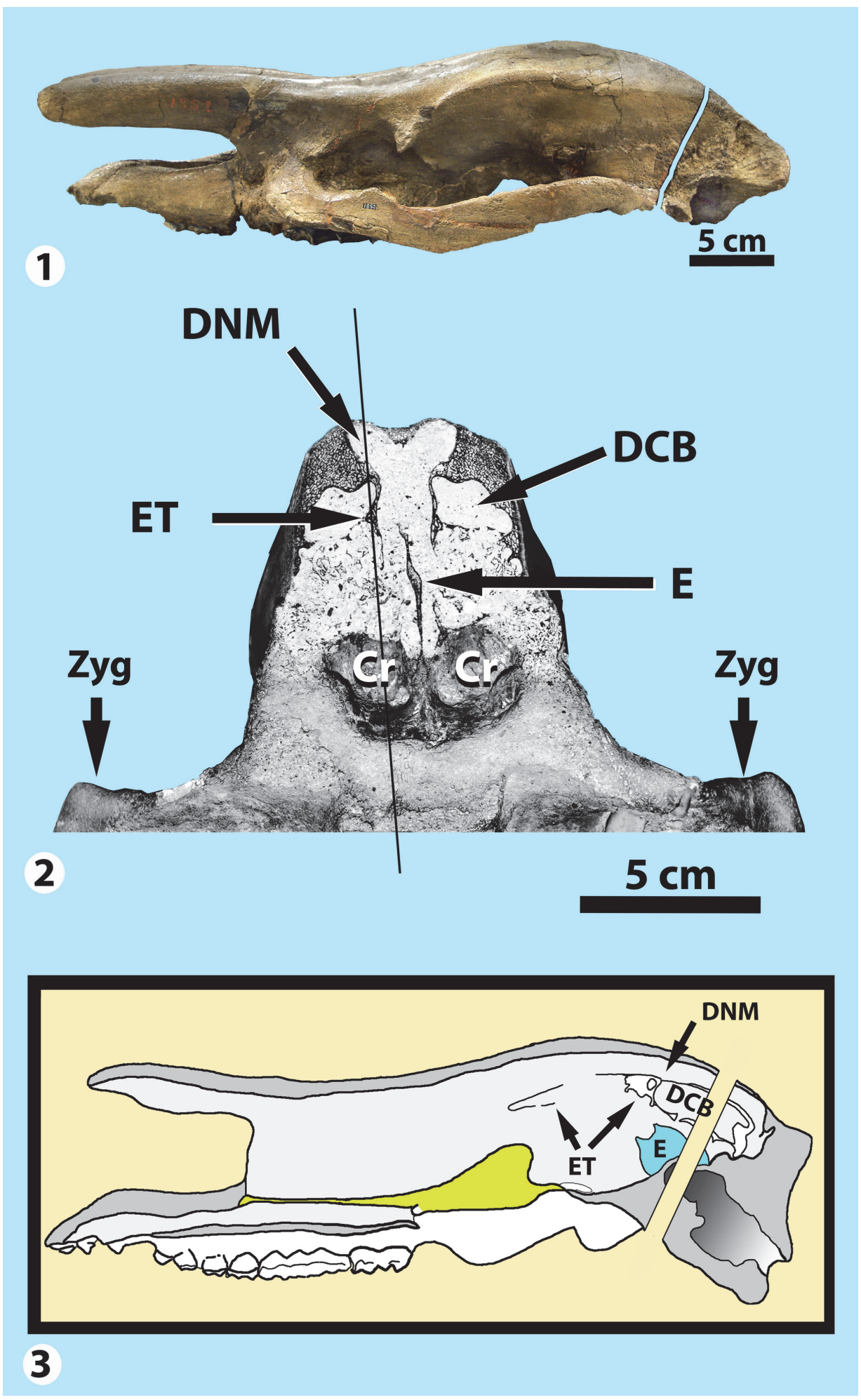

FIGURE 6. Skulls of Sphenocoelus (= Dolichorhinus). 1, AMNH 1852 in lateral view showing location of transverse section near back of skull; 2, transverse section of AMNH 1852 through anterior-most part of braincase looking anteriorly; 3, reconstructed sagittal section of AMNH 1851 (from Figure 5.3) showing the approximate plane of the transverse section in AMNH 1852 relative to internal structures. Abbreviations: Cr, cribriform plate of ethmoid; DCB, dorsal conchal bulla; DNM, dorsal nasal meatus; E, ethmoid (perpendicular plate); ET, ethmoturbinate; Zyg, zygomatic arch. Thin diagonal line in middle image approximates the plane of the sagittal section shown in Figure 5.2. 
entire internal narial opening, leaving little room for a functional air passageway. The air stream in both taxa opens posterior to the vomer at the functional internal nares, which I identify as the vomerine notch. This opening is well posterior to the anatomical internal nares. Again, this posterior displacement is greater in Sphenocoelus than in Metarhinus.

The so-called "vomerine" plate is observed to bisect the vomerine notch in Sphenocoelus, and this was also probably the case in Metarhinus. Thus, two air streams exit into the nasopharynx as in all mammals.

The greatest challenge to the interpretation offered here is the location and structure of the septal cartilage in typical mammals. The cartilage normally sits in the u-shaped septal groove of the vomer. Since this is the proposed air passageway, the cartilage would require significant modification in order for the vomer to function in its suggested capacity. In essence, the vomer and septal cartilage would need to remain separated from each other so that air might be channeled over or through the vomer.

Classical embryological interpretation makes this difficult to envision. According to classic embryology (e.g., Neskey et al., 2009), the nasal septum forms as a downward projection from the roof of the nasal cavity, which then joins the palatal processes of the maxillae as they fuse to form the secondary palate. The septum then (presumably) differentiates into the septal cartilage, the perpendicular plate of the ethmoid, and the vomer.

However, Botti et al. (2017) contend that the vomer forms by midline fusion of two vomerine precursors that are associated with the maxillae in the developing secondary palate. The vomer is then displaced dorsally to meet the perpendicular plate of the ethmoid and the septal cartilage. Thus, the nasal septum consists of two distinct parts: a dorsal or olfactory septum (formed by the perpendicular plate of the ethmoid and the septal cartilage) and a ventral or respiratory septum (formed by the vomer, the crest of the maxilla, and crest of the palatine).

Hypothetically, therefore, it would be possible for the vomer and septal cartilage never to meet. Thus, the respiratory septum below would be wholly or partially isolated from the olfactory septum above, allowing for the vomer to channel air.

Regrettably, the septal cartilage is exceedingly unlikely to be preserved in any fossil. Barring the chance discovery of a specimen in which the cartilage is ossified (or, at least, calcified), we are unlikely to ever know its appearance or relation to other structures in the nasal cavity. However, the discovery of additional specimens with well-preserved ethmoids and vomers might help to elucidate the anatomy of the soft structures and, either, support or refute the interpretation offered here.

It should be noted that there is probably some physiological advantage to retaining at least a partial septum to divide the airstream into right and left parts. The nasal cycle, which has been studied since the late nineteenth century, involves the periodic congestion and decongestion of the nasal mucosa alternating from side to side every few hours. Thus, the flow of air through the nasal cavity is asymmetrical, with each side temporarily dominating the other (Hasegawa and Kern, 1977; Eccles, 1996; Sobel et al, 1999).

It has been demonstrated that the side of the nasal cavity with the faster airflow is more sensitive to high-sorption odorants and the side with the slower airflow is more sensitive to low-sorption odorants. Therefore, the olfactory system provides the brain with two disparate images of the olfactory world, improving overall olfactory acuity by increasing the range of molecules that can be detected with a single sniff (Sobel et al., 1999).

Furthermore, it has been suggested that, by slowing airflow on one side, it enhances the moistening, warming, and filtering of air, which are vital functions of the nasal cavity (White et al., 2015). It has also been suggested that the congestion/ decongestion cycle may create a pumping mechanism for the generation of plasma exudate, which contains antibodies, elements of the complement system, and other chemicals that fight infection (Eccles, 1996).

Evidence that a septum at least partially divided the nasal cavity is found in Sphenocoelus. Part of the perpendicular plate of the ethmoid was preserved in AMNH 1852 showing that the posterior-most recesses of the nasal cavity had a medial partition. However, the perpendicular plate did not extend all the way to the skull roof at this location (although it is possible that there was a cartilaginous extension reaching the skull roof that was not preserved in the fossil). Furthermore, in AMNH 13164 the "vomerine" plate was found to bisect the vomerine notch, thus creating two parallel airstreams at the location where air exited the nasal cavity (the functional internal nares). Presumably, the anatomy of Metarhinus would be similar, but at present, there is no specimen demonstrating this.

Mader (2009) discussed the functional significance of these unusual narial adaptations, sug- 
gesting two possibilities: that they might have been an aquatic adaptation or an adaptation to enhance olfaction. Regarding an aquatic adaptation, the unusual narial features of Metarhinus and Sphenocoelus essentially extend the secondary palate, possibly helping to isolate the nasal cavity from the mouth (which, in an aquatic form, may be filled with water from time to time). Riggs (1912, p. 36) was actually the first to make this suggestion (concerning Sphenocoelus $=$ Dolichorhinus) and speculated that it was an adaptation for feeding upon submerged plants. Osborn (1929, p. 399) acknowledged Riggs' interpretation and noted that, "the backward shifting and closure of the hinder border of the palate is an obvious advantage to animals feeding partly in the water and is characteristic of many water-living forms."

However, the vomerine notch (the presumed functional internal nares in these forms) is dorsal to or just posterior to the soft palate (whose location is indicated by the pterygoids), which already separates the oral cavity from the nasopharynx. Hence, it seems unlikely that the placement of the functional internal nares at this location significantly enhances separation of the air stream from the oral cavity.

Further drawing into question whether this is an aquatic adaptation, is the possibility that brontotheres might not have been able to breathe through the mouth at all, thus negating a need to physically isolate the mouth from the nasal cavity. In horses the epiglottis extends through the oropharynx and overlaps the posterior margin of the soft palate, completely blocking off the mouth from the air passageway (Holcombe, 1998; Dixon and Collins, 2010). Thus, horses normally cannot breathe through the mouth and are obligate nasal breathers (Franklin et al., 2002; Dixon and Collins, 2010). The Black Rhinoceros (Diceros bicornis) also has at least some difficulty breathing through the mouth and, if not an obligate nasal breather, may be described as a highly preferential nasal breather (Mathew Gerard and Anthony Blikslager, personal communication, 2018). Therefore, it is possible that brontotheres, the perissodactyl relatives of horses and rhinos, could have had the same limitation, removing the need to isolate the mouth from the airstream in an aquatic form.

Increasingly, I favor the second interpretation wherein the anatomy is an adaptation that enhances olfaction. The skulls of both Metarhinus and Sphenocoelus are elongated and, in the case of Sphenocoelus, the skull is so extremely elongated that it is described by Osborn (1929) and
Mader (1989, 1998, and 2008) as "hyperdolichocephalic." Owing to the fact that the brontothere brain was extremely small in size compared to that of many modern mammals (note brain size in Figures 3 and 5.3), there is a considerable distance between the internal nares and the olfactory epithelium, which is associated with the ethmoid at the anterior edge of the cranial cavity. This is especially true in Sphenocoelus.

If the air stream were to exit the nasal cavity at the usual location (the internal nares) it would not reach the olfactory epithelium (although some air might waft in that direction). Hence the sense of smell might be negatively impacted.

By channeling the air over or through the vomer, however, it is able to pass further posteriorly before exiting and is aimed directly toward the ethmoid and olfactory epithelium (see Figures 3 and 5.3). The vomerine notch forms a convenient exit for the air, although as noted above, an opening through the soft tissue covering this part of the skull would have had to evolve.

Given my speculation that the redirection of the airstream over or through the vomer is an olfactory adaptation, it is particularly interesting to note that the structures surrounding the vomeronasal organ are also modified. Mihlbachler (2008) observed that the rostral cavity, which houses the vomeronasal organ, is covered over dorsally in Sphenocoelus (AMNH 13164). Hence the vomeronasal organ was situated in a bony chamber rather than lying openly in the floor of the nasal cavity (see Figure 5.2). Mihlbachler indicated that the vomeronasal organ was separated from the nasal chamber, but, from the specimens that I have examined, that is not certain (although it is a definite possibility).

Mihlbachler (2008) also noted that the roof overlying this chamber is formed largely from a pair of thin bones that emerge horizontally from the nasal cavity and insert into a notch formed by the premaxillae (based on AMNH 13164). Mihlbachler suggested that these bones represent anterior extensions of the maxilloturbinates, but once again, I believe that the vomer is a more likely candidate. In mammals that I have examined (e.g., Equus, Canis, Panthera, Odocoileus, Tayassu, Papio) the vomer contacts the premaxilla medially in this general location and, the flat, horizontal structure is more suggestive of that bone than the rounded, scroll-like turbinates. Although Mihlbachler describes these as a pair of structures (the mammalian vomer is unpaired), the vomer is embryologically derived from two centers of ossifi- 
cation that later fuse (Sisson, 1910; Botti et al., 2017), and the vomer is paired in primitive amniotes (Jankowski, 2013). If the vomer and septal cartilage underwent extensive modification (as suggested in this paper), it is hypothetically possible that the two parts of the vomer could remain atavistically separate, either in whole or in part. If this is the vomer, it has been elevated far above the floor of the nasal cavity, probably supported from below by the crest of the maxilla.

As Mihlbachler noted, Metarhinus (UCM 44939) also appears to share this morphology, although I cannot confirm that there is an isolated chamber in which the vomeronasal organ sat. Hence, no such space is indicated in the reconstruction appearing in Figure 3, although it is definitely possible that one was present.

If brontotheres were obligate or near-obligate nasal breathers, it is unlikely that the incisive duct communicated with the oral cavity through the incisive foramen. There is no such communication in the horse (Kostov, 2007). Since the vomeronasal organ is a blind pocket that opens anteriorly, it is difficult to envision how it would be able to function effectively enclosed within a bony chamber with little or no access to the nasal cavity. Therefore, if brontotheres were obligate nasal breathers, there is a possibility that the vomeronasal organ was not functional in Metarhinus or Sphenocoelus. If brontotheres could breathe freely through the mouth (unlike horses or rhinos) then, in these two taxa, the vomeronasal organ may have sensed oral stimuli only.

As noted above, the taxonomy of Mader (1998, 2008, and the present paper) differs somewhat from that of Mihlbachler (2008), who is the other major recent reviser of North American brontotheres. That author recognized Dolichorhinus as a genus that is distinct from Sphenocoelus, while in the present paper these genera are regarded as synonyms. If the taxonomy of Mihlbachler were to be applied, then the morphology ascribed here to Sphenocoelus, would pertain to the genus Dolichorhinus. The species of Sphenocoelus/Dolichorhinus discussed in the present paper $(S$. hyognathus) was the only species of Dolichorhinus recognized as valid by Mihlbachler.

Both Mader (1998, 2008) and Mihlbachler (2008) recognized Metarhinus fluviatlis (the spe- cies of Metarhinus discussed in the present paper) as valid. Both also recognized a second valid species to which Mader applied the name M. diploconus, but to which Mihlbachler applied the name $M$. abbotti. Mader regarded M. abbotti as a junior synonym of $M$. diploconus, while Mihlbachler regarded the type of $M$. diploconus as representing a new genus, which he named Fossendorhinus. Mader (2009) regarded Fossendorhinus as a junior synonym of Metarhinus (also my view in the current paper). Mihlbachler and Deméré (2010) recognized a third species of Metarhinus as valid, $M$. pater. Previously Mader (2008) had regarded $M$. pater as a possible junior synonym of $M$. diploconus and Mihlbachler (2008) regarded it as a nomen dubium. Mihlbachler and Deméré's conclusion that M. pater is a valid species was based on a detailed analysis of newly discovered specimens, which they referred to that species. I have not had the opportunity to examine the specimens in question, but provisionally accept their conclusion regarding the validity of this taxon.

\section{ACKNOWLEDGMENTS}

I am extremely thankful to E.E. Sarmiento for an informative discussion concerning mammalian nasal anatomy. It was he who was the first to recognize that the peculiar bone in the pterygoid region of UCM 44939 was the vomer. I am also indebted to M. Gerard and A. Blikslager of North Carolina State University College of Veterinary Medicine for expert information concerning obligate nasal breathing in the rhinoceros. Regarding veterinary medicine, I also thank R. Carlan for informative discussions concerning the anatomy and physiology of respiration. I thank my colleague, R. Hammer, for her assistance in handling specimens and helping me to evaluate the plane of section in AMNH 1851. I am grateful to the curators and staff at the American Museum of Natural History (New York), Field Museum of Natural History (Chicago), and University of Colorado Museum (Boulder) for their hospitality and for permitting me to examine specimens under their care. I thank two anonymous reviewers for their insightful comments on the manuscript, which led to improvements in the paper. 


\section{REFERENCES}

Botti, S., Rumeau, C., Gallet, P., and Jankowski, R. 2017. Vomero-premaxillary joint: a marker of evolution of the species. European Annals of Otorhinolaryngology, Head and Neck Diseases, 134:83-87. https://doi.org/10.1016/j.anorl.2016.11.002

Cook, H.J. 1926. New Eocene titanotheres from Moffat County, Colorado. Proceedings of the Colorado Museum of Natural History, 6(3):12-18.

Dixon. P.M. and Collins, N. 2010. The equine epiglottis. Equine Veterinary Education, 16(6):299301. https://doi.org/10.1111/j.2042-3292.2004.tb00315.x

Eccles, R. 1996. A role of the nasal cycle in respiratory defence. European Respiratory Journal, 9:371-376. https://doi.org/10.1183/09031936.96.09020371

Eisenmann, V., Alberdi, M.T., DeGiuli, C., and Staesche, U. 1988. Studying fossil Horses. Volume 1: Methodology, p. 1-71. In Woodburne, M.O. and Sondaar, P.Y. (eds.), Collected Papers after the "New York International Hipparion Conference, 1981". Brill, Leiden.

Franklin, S.H., Naylor, J.R.J., and Lane, J.G. 2002. Effect of dorsal displacement of the soft palate on ventilation and airflow during high-intensity exercise. Equine Veterinary Journal Supplement 34, Equine Exercise Physiology, 6:379-383. https://doi.org/10.1111/j.20423306.2002.tb05452.x

Hasegawa, M. and Kern, E.B. 1977. The human nasal cycle. Mayo Clinic Proceedings, 52(1):2834.

Hatcher, J.B. 1895. On a new species of Diplacodon, with a discussion of the relations of that genus to Telmatotherium. American Naturalist, 29(348):1084-1090.

Holcombe, S.J. 1998. Neuromuscular regulation of the larynx and nasopharynx in the horse. Proceedings of the Annual Convention of the American Association of Equine Practitioners, 44:26-29.

Jankowski, R. 2013. The Evo-Devo Origin of the Nose, Anterior Skull Base and Midface. Springer, New York, New York. https://doi.org/10.1007/978-2-8178-0422-4

Kostov, D.L. 2007. Vomeronasal organ in domestic animals (a short survey). Bulgarian Journal of Veterinary Medicine, 10 (1):53-57.

Mader, B.J. 1989. The Brontotheriidae: a systematic revision and preliminary phylogeny of North American genera, p. 458-484. In Prothero, D.R. and Schoch, R.M. (eds.), The Evolution of Perissodactyls. Oxford Monographs on Geology and Geophysics (15). Oxford University Press, New York.

Mader, B.J. 1998. Brontotheriidae, p. 525-536. In Janis, C.M., Scott, K.M., and Jacobs, L.L. (eds.), Evolution of Tertiary Mammals of North America. Volume I: Terrestrial Carnivores, Ungulates, and Ungulatelike Mammals. Cambridge University Press, New York.

Mader, B.J. 2008. A species level revision of Bridgerian and Uintan brontotheres (Mammalia, Perissodactyla) exclusive of Palaeosyops. Zootaxa, 1837:1-85.

Mader, B.J. 2009. The cranial anatomy of Metarhinus (Mammalia, Perissodactyla, Brontotheriidae). Journal of Vertebrate Paleontology, 29(4):1300-1305. https://doi.org/ 10.1671/039.029.0429

Marsh, O.C. 1873. Notice of new Tertiary mammals. American Journal of Science, $3 d$ series, 5:407-411, 485-488.

Mihlbachler, M.C. 2008. Species taxonomy, phylogeny, and biogeography of the Brontotheriidae (Mammalia: Perissodactyla). Bulletin of the American Museum of Natural History, 311:1-475. https://doi.org/10.1206/0003-0090(2008)501[1:STPABO]2.0.CO;2

Mihlbachler, M.C. and Deméré, T.A. 2010. Phylogenetic status of Metarhinus pater (Brontotheriidae: Perissodactyla) from southern California and species variation in Metarhinus from the middle Eocene of North America. Journal of Vertebrate Paleontology, 30(4):1229-1244. https://doi.org/10.1080/02724634.2010.483568

Neskey, D., Eloy, J.A., and Casiano, R.R. 2009. Nasal, septal, and turbinate anatomy and embryology. Otolaryngologic Clinics of North America, Surgical Management of Nasal Obstruction: Rhinologic Perspective, 42:193-205. https://doi.org/10.1016/j.otc.2009.01.008

Osborn, H.F. 1895. Fossil mammals of the Uinta Basin, Expedition of 1894. Bulletin of the American Museum of Natural History, 7 (2):71-105.

Osborn, H.F. 1908. New or little known titanotheres from the Eocene and Oligocene. Bulletin of the American Museum of Natural History, 24 (32):599-617. 
Osborn, H.F. 1929. The titanotheres of ancient Wyoming, Dakota, and Nebraska. U.S. Geological Survey, Monograph 55 (2 volumes). United States Government Printing Office, Washington, D.C.

Owen, R. 1848. Description of teeth and portions of jaws of two extinct anthracotherioid quadrupeds (Hyopotamus vectianus and Hyop. bovinus) discovered by the Marchioness of Hastings in the Eocene deposits on the N.W. coast of the Isle of Wight: with an attempt to develop Cuvier's idea of the classification of pachyderms by the number of their toes. Quarterly Journal of the Geological Society of London, 4:103-141.

Peterson, O.A. 1914. A small titanothere from the lower Uinta beds. Annals of the Carnegie Museum, 9(1-2):53-57.

Peterson, O.A. 1924. Osteology of Dolichorhinus longiceps Douglass, with a review of the species of Dolichorhinus in the order of their publication. Memoirs of the Carnegie Museum, 9(4):405-473.

Riggs, E.S. 1912. New or little known titanotheres from the lower Uinta Formation. Field Museum of Natural History Publication 159, Geological Series, 4:17-41.

Sisson, S. 1910. A Text-Book of Veterinary Anatomy. W. B. Saunders Company, Philadelphia, Pennsylvania.

Sobel, N., Khan, R.M., Saltman, A., Sullivan, E.V., and Gabrieli, J.D.E. 1999. The world smells differently to each nostril. Nature, 402:35. https://doi.org/10.1038/46944

White, D.E., Bartley, J., and Nates, R.J. 2015. Model demonstrates functional purpose of the nasal cycle. BioMedical Engineering Online, 14:38. https://doi.org/10.1186/s12938-0150034-4 